\title{
Physiological and anatomical differentiation of two sympatric weed populations
} \author{
Scheibe ${ }^{4}$ \\ 1 Department of Botany, University of Osnabrück, Osnabrück, Germany \\ 2 School of Biological and Chemical Sciences, Queen Mry University of London, London, United Kingdom \\ 3 Institute of Botany, University of Natural Resources and Applied Life Sciences, Vienna, Austria \\ 4 Plant Physiology, University of Osnabrück, Osnabrück, Germany \\ 5 Faculty of Biology/Bielefeld University, Department of Biochemistry \& Physiology of Plants, Bielefeld, Germany \\ Corresponding Author: Barbara Neuffer \\ Email address: neuffer@biologie.uni-osnabrueck.de
}

Barbara Neuffer $^{\text {Corresp., } 1}$, Michael Schorsch ${ }^{2}$, Steffen Hameister ${ }^{3}$, Johannes Knüsting ${ }^{4}$, Jennifer Selinski ${ }^{5}$, Renate

In the vineyards of Rhineland-Palatinate (Germany), two different types of Shepherd's Purse coexist: (1) the common type called 'wild type', and (2) the decandric type called Capsella apetala or 'Spe' with four stamens in place of petals. In this study, we compare the anatomical and physiological characters of rosette leaves of the respectice types. Progeny of individual plants was cultivated in growth chambers under low- and high-light conditions. Under low-light conditions, the stomata densities of the adaxial and abaxial epidermis did not differ between the two types. When grown under high-light conditions, wild type and Spe, both exhibited increased stomata densities compared to low-light conditions, but Spe to a lesser extent than the wild type. The maximal photosynthetic capacity of Spe was lower in both, low-light and high-light conditions compared to wildtype plants. Even under ambient and sub-ambient $\mathrm{CO}_{2}$ concentrations, Spe seemed to be less productive. The less effective $\mathrm{CO}_{2}$ assimilation of the Spe mutant $C$. apetala was accompanied by later flowering. This fact prolonged the vegetative phase of Spe by about two weeks and was sufficient for the maintenance of both populations stably over years. 


\section{Research article}

2

3 Physiological and anatomical differentiation of two sympatric weed

4 populations

6 Barbara Neuffer ${ }^{1 *}$, Michael Schorsch$^{4}$, Steffen Hameister ${ }^{3}$, Johannes Knüsting ${ }^{2}$,

7 Jennifer Selinski ${ }^{5}$, Renate Scheibe ${ }^{2}$

1 Department of Botany, University of Osnabrueck, Osnabrück, Germany

2 Department of Plant Physiology, University of Osnabrueck, Germany

3 Institute of Botany, Department of Integrative Biology and Biodiversity

12 Research, University of Natural Resources and Life Sciences, Vienna, Austria

${ }^{4}$ School of Biological and Chemical Sciences, Queen Mary University of London,

14 Great Britain

5 Department of Biochemistry \& Physiology of Plants, Faculty of Biology,

* Corresponding Author: 


\section{Abstract}

In the vineyards of Rhineland-Palatinate (Germany), two different types of

Shepherd's Purse coexist: (1) the common type called 'wild type', and (2) the decandric type called Capsella apetala or 'Spe' with four stamens in place of petals. In this study, we compare the anatomical and physiological characters of rosette leaves of the respectice types. Progeny of individual plants was cultivated in growth chambers under low- and high-light conditions. Under low-light conditions, the stomata densities of the 34 adaxial and abaxial epidermis did not differ between the two types. When grown under high-light conditions, wild type and Spe, both exhibited increased stomata densities compared to low-light conditions, but Spe to a lesser extent than the wild type. The maximal photosynthetic capacity of Spe was lower in both, low-light and high-light conditions compared to wild-type plants. Even under ambient and sub-ambient $\mathrm{CO}_{2}$ concentrations, Spe seemed to be less productive. The less effective $\mathrm{CO}_{2}$ assimilation

40 of the Spe mutant $C$. apetala was accompanied by later flowering. This fact prolonged 41 the vegetative phase of Spe by about two weeks and was sufficient for the maintenance 42 of both populations stably over years.

\section{Introduction}

In the vineyards of southwestern Germany (Rhineland-Palatinate) two morphologically distinct types of the common annual weed Shepherd's Purse (Capsella

47 bursa-pastoris (L.) Medik., Brassicaceae) occur side by side (Reichert 1998, Fig. 1). 
48 The two populations can readily be differentiated by their characteristic flower structure.

49 Wild type (wt) C. bursa-pastoris flowers exhibit the conserved body plan of

50 Brassicaceae: it comprises four sepals in the first, four petals in the second, six stamens

51 in the third, and two fused carpels in the fourth, the innermost whorl (Fig. 1).

In contrast, the flowers of the floral variant, also referred to as Spe (Hameister and Neuffer 2017, Nutt et al. 2006), can easily be identified by four additional stamens replacing the wild-type petals thus giving it its unique decandric phenotype (Fig. 1). This

floral variant of C. bursa-pastoris has initially been described as C. apetala Opiz (Opiz 1821), a terminology which we follow here to differentiate between both types. Notably, the decandric flower shape does not affect floral symmetry, but the lack of petals might have an impact on pollination success (Hameister and Neuffer 2017). Recent field surveys in vineyards revealed that the wild type is the predominant taxon with tens of thousands of individuals, and the Spe occurs with a stable frequency of about $10 \%$

61 (Hameister et al. 2009). Intriguingly, potential pollinators, especially wild bees, and 62 hoverflies, tend to prefer one over the other type, probably due to differing volatile 63 emissions of the two flower types (Ziermann et al. 2009, Hameister and Neuffer 2017,

64 Fig. 1). Recent investigations by Hameister and Neuffer (2017) demonstrated that

65 flower induction is delayed in Spe when compared with wild type in both, field and controlled greenhouse conditions. Notably, the authors could show that in an

67 overlapping period both types are fertile. However, both taxa exhibit a high "selfing" rate 68 and a low crossing rate between the two flower types has been found (Hameister and

69 Neuffer 2017, Fig. 1). Furthermore, pollen tubes of C. apetala self-pollen grew faster

70 compared with C. apetala crossed with wild-type pollen (spe $\times$ wt, Neuffer and Paetsch 
71 2013). Field experiments in the Botanical Garden of the University of Osnabrueck

72 revealed that the two types differ in the physiological investments into their respective

73 offspring. Wild-type individuals produced more siliques per plant, whereas the Spe

74 generated a higher number of seeds in the siliques (Hameister and Neuffer 2017). The

75 total seed output per plant was balanced among the two flower types (Hameister and

76 Neuffer 2017) indicating that the fitness-related factor seed production remains 77 unaffected.

Taken together, the previous investigations lead to the assumption that $C$. bursa-

pastoris and $C$. apetala are separated by several smooth to strong isolation barriers.

Thus, they form two morphologically distinct types that grow sympatrically in the

81 vineyards of southwestern Germany (Reichert 1998). Further support for this hypothesis

82 can be extracted from genetic work by Hameister et al. (2009). Here, the authors

83 showed that wild type and Spe differed in their isozyme genotype. Furthermore, the

84 genetic difference was confirmed by creating a mapping population between a wild-type

85 individual and a Spe individual followed by comparative linkage analysis (Hameister et 86 al. 2013).

In this study, we focus on the properties of the leaves of the two types in the 88 vegetative stage when the plant accumulates assimilates which then are used for

89 building up the inflorescence and production of seeds. Rosette leaves provide the basis

90 for an individual to withstand harsh environmental conditions, e.g., cold temperatures,

91 high irradiation, and drought stress. When the apical meristem switches from the

92 vegetative to the reproductive state, no further rosette leaves are generated. The

93 question was: what is the contribution of leaf differentiation to the ecotypic variation 
94 between sympatrically growing individuals with normal (wild-type) flowers in contrast to

95 individuals with decandric (Spe) flowers? Here, we studied the ecotypic differentiation of

96 the rosette leaf after growth under stress (high-light) and no stress (low-light) conditions

97 using anatomical and physiological methods.

\section{Material and Methods}

Plant material and cultivation of plants

Seeds of individual plants of Capsella bursa-pastoris (wild type) and Capsella

102 apetala Opiz (Spe) have been collected in the vineyards located near to Gau-

103 Odernheim (Rhineland-Palatinate, 25 km southwest of Mainz, 49.7847 N, 8.1942 E,

104 elevation $150 \mathrm{~m}$, Germany) and subsequently stored at minus $20^{\circ} \mathrm{C}$ in the seed gene

105 bank of the Botanical Garden of Osnabrueck. The material refers to the gene bank

106 numbers 1951/19 and 1960/25 for the wild type and 1956/5 and 1961/4 for the

107 decandric type. Note that plant material subjected to photophysiological and anatomic

108 characterization in this publication is derived material from seeds of two independent

109 population subgroups of each flower morphological type. Plants were initially cultivated

110 under controlled conditions programmed with a 12-h photoperiod per day, resulting in

111 four subgroups with six individuals each. The temperature was adjusted to $15^{\circ} \mathrm{C}$ during

112 day time and $5^{\circ} \mathrm{C}$ during the night phase (initial growth conditions for seedlings). After

113 six weeks, the plants were divided into two experimental groups. Three individuals of

114 each subgroup were transferred into two different light conditions in an 8-h light period 115 at $20^{\circ} \mathrm{C}$ : (i) high-light setting $\left(600 \mu\right.$ mol quanta $\left.\mathrm{m}^{-2} \mathrm{~s}^{-1}\right)$; (ii) low-light setting 
$116\left(100 \mu \mathrm{mol}\right.$ quanta $\left.\mathrm{m}^{-2} \mathrm{~s}^{-1}\right)$ (Fig. 2). Later on sister individuals have been planted in the

117 experimental field of the Botanical garden.

118

119

Morphology and anatomy

120

Leaf characterization was performed on three-month-old leaves. Epidermal leaf

121 tissue was prepared for microscopic examination (Fig. 3) by a customized technique

122 applying nail polish. After solidification of the nail polish, the epidermal cell layer was

123 removed by transparent adhesive tape (Tesafilm). The nail polish imprint, including

124 adhesive tape, was observed with a microscope. Subsequently, stomata were

125 quantified in a representative area of $400 \times 400 \mu \mathrm{m}^{2}$ on one rosette leaf of every

126 individual plant (Fig. 4).

127

128

Photosynthetic characterization

129

All measurements were performed using one fully expanded rosette leaf from

130 plants two months after sowing when they did not yet flower. The $\mathrm{CO}_{2}$ gas exchange

131 was measured using the LI-6400/XT Portable Photosynthesis System (LI-COR

132 Environmental, Lincoln, NE, U.S.A.). All measurements were conducted under

133 saturating light intensities of $800 \mu \mathrm{mol}$ quanta $\mathrm{m}^{-2} \mathrm{~s}^{-1}$ at $20^{\circ} \mathrm{C}$. The relative humidity was

134 adjusted to approximately $50 \%$. The rate of $\mathrm{CO}_{2}$ assimilation $(\mathrm{A})$ was measured as a

135 function of sub-stomatal $\mathrm{CO}_{2}$ concentration $\left(\mathrm{C}_{\mathrm{i}}\right)$. $\mathrm{C}_{\mathrm{i}}$ values were applied in the following

136 order: 400 ppm; 200 ppm; 100 ppm; 50 ppm; 0 ppm; 400 ppm; 600 ppm; 1000 ppm;

$1371750 \mathrm{ppm}$. Here, the initial decrease in $C_{i}$ concentration was chosen to ensure a

138 sufficient leaf conductance. The leaf conductance is widely considered as an indicator 
139 of effective gas exchange of the leaf with the surrounding environment and is

140 predominantly determined by the extent to which the stomata are opened. By applying

141 decreasing $\mathrm{CO}_{2}$ concentrations in the first half of a photosynthesis measurement, a

142 conductance of at least 0.2 was maintained throughout the entire measurement

143 (Fig. S1). In this way, a possible limitation of $\mathrm{CO}_{2}$ assimilation due to inefficient gas

144 exchange was avoided. Data points were logged within 2 min after the start of each $C_{i}$

145 concentration when infrared gas analyzer (IRGA) parameters reached a steady-state

146 value (raw data for 22 individuals Suppl. Tab. S2).

147

Determination of flowering time under field conditions

149 Seventy days after sowing sister plants were planted into the experimental field of the

150 Botanical Garden Osnabrueck and flowering time was determined by observation of the

151 emerging inflorescence bud.

152

153

\section{Results}

154

Stomata density on both sides of rosette leaves

155

After growth for three months in the climate chambers, epidermal peel from upper and lower leaf surfaces was prepared and inspected by light microscopy (Fig. 3). The number of stomata was determined for wild type and Spe after growth in low light and high light. As expected, the stomata density of the lower epidermis was found to be higher compared to the upper surface for both types in all light conditions (Fig. 4). When grown under low-light conditions, no obvious differences could be detected between the

161 two flower types. In contrast, both types after growth under high-light conditions 
162 exhibited a significantly increased stomata density on both leaf surfaces (Fig. $\mathbf{3}$ and $\mathbf{4}$,

163 Suppl. Table S1). Interestingly, the number of stomata on the adaxial (upper) surface of

164 the leaves of Spe was significantly less increased when compared with wild-type

165 individuals after growth in high-light conditions (Fig. 4). Notably, this trend could not be

166 observed for the abaxial (lower) epidermis under the same conditions.

167

Photosynthetic characteristics of rosette leaves

169 To further elucidate the impact of the differentially increased stomata density observed

170 in plants grown under high-light conditions, the photosynthetic efficiency was

171 determined under saturating light using gas-exchange measurements. The rate of

172 carbon assimilation $(\mathrm{A})$ in response to various externally applied $\mathrm{CO}_{2}$ concentrations

173 given as internal $\mathrm{CO}_{2}\left(\mathrm{C}_{\mathrm{i}}\right)$ was monitored for wild type and Spe plants. The resulting

$174 \mathrm{~A} / \mathrm{C}_{\mathrm{i}}$ plots show the typical saturation behavior for all plants grown under both light

175 conditions (Fig. 5).

176 Photosynthesis was limited by the availability of $\mathrm{CO}_{2}$ until a calculated internal $\mathrm{CO}_{2}$

177 concentration $\left(C_{i}\right)$ of approximately $350 \mathrm{ppm}$ was reached. The initial linear increase of

$178 \mathrm{CO}_{2}$ assimilation reflects the maximal carboxylation rate of RubisCO (Fig. 5, C and D).

179 Above $350 \mathrm{ppm}$, the curves enter saturation as net photosynthesis becomes limited by

180 other factors such as the electron transport and, at higher $\mathrm{CO}_{2}$ concentrations, the

181 utilization of triose phosphate. At saturating $\mathrm{CO}_{2}$ concentrations, maximum net-

182 photosynthesis rates of Spe were always lower than of the wild type when cultivated

183 under both, low- and high-light conditions (Fig. 5, A and B). However, the initial

184 carboxylation rate was rather similar for the two types. At ambient $\mathrm{CO}_{2}$ concentrations of 
185 approximately $400 \mathrm{ppm}$ which more accurately reflect the photosynthetic efficiency of

186 the plants the rates of $\mathrm{CO}_{2}$ assimilation are higher when the plants have been grown

187 under high light, and significantly lower when grown under low-light conditions (Fig. 5, C

188 and D). No premature stomatal closure had limited gas exchange as shown by plotting

189 the stomatal conductance (gs) against the $C_{i}$ values for each measurement (Suppl. Fig.

190 S1).

191

192

Flowering time

193 In order to identify traits of Spe, which explain the observed stable co-existence in the

194 field even with a lower photosynthetic performance, the flowering time was analysed.

195 After 70 days sister plants (wt 72 individuals, Spe 63 individuals) were transferred from

196 the initial growth conditions for seedlings to the experimental field in the Botanical

197 Garden of Osnabrueck. Under these field conditions, wild-type individuals in average

198 flowered about two weeks earlier $(x=77.64+/-3.562$ days after sowing) than Spe

199 individuals ( $x=91.75+/-12.618$ days after sowing (Fig. 6).

\section{Discussion}

202

Finely scaled ecotypic differentiation for Shepherd's Purse is well known and 203 quite substantial regarding germination, the onset of flowering, and growth forms (Linde 204 et al. 2001, Neuffer and Linde 1999, reviewed in Neuffer et al. 2011). Already at the 205 beginning of the $20^{\text {th }}$ century, Almquist (1907) determined several elementary species

206 based on fruit and rosette-leaf morphology. This variable leaf morphology attracted the 207 interest of the geneticist Shull $(1909,1911)$. Aksoy et al. (1999) included the system of 
208 Shull in their attempt towards a simplified taxonomy of C. bursa-pastoris and lanetta et

209 al. (2007) widened the system of Shull.

210 Combining anatomical and physiological traits provides the first insight into the

211 value of leaf differentiation other than the morphology of leaf types after Shull (Neuffer

212 et al. 2018). The ecotypic differentiation of the leaf in various habitats and conditions at

213 geographically and climatically different places of origin of many populations is an

214 obvious character that somehow serves adaptation and persistence in new growth

215 conditions. The occurrence of a specific flower morphology of C. bursa-pastoris

216 individuals in the vineyards south of Mainz in southwestern Germany is known for quite

217 some time (Reichert 1998). At first sight, this natural mutant is predominantly important

218 for studies of plant geneticists (Nutt et al. 2006, Ziermann et al. 2009, Hintz et al. 2006,

219 Hameister et al. 2013). With a more detailed analysis, several traits became apparent,

220 and population studies led to the insight that the wild type of $C$. bursa-pastoris and its

221 variant C. apetala even form two different ecotypes, sympatrically occurring at one

222 place over many years (Hameister and Neuffer 2017, Hameister et al. 2009). This

223 differentiation is also evident from genetic differences (Isozyme Genotypes, AFLPs, see

224 Hameister et al. 2009).

225 As a typical leaf characteristic, stomata density was determined in the 226 experimental populations (Fig. 4). In general, all leaves had developed more stomata

227 under high-light growth conditions than in low-light as was already observed for 228 C. bursa-pastoris provenances from Morocco and Norway, but not from Russia (Neuffer

229 et al. 2018). Furthermore, stomatal density on the abaxial epidermis was about twice as

230 high as in the adaxial leaf surface both in wild type and Spe after growth under high 
231 light. However, as an exception, Spe had not increased its stomata density on the upper

232 leaf surface to the same extent as did the wild type. It had developed about $35 \%$ fewer

233 stomata per area unit on the upper surface of its rosette leaves as compared to the wild

234 type (Fig. 4). A possible explanation for this phenomenon might lie in the fact that the

235 incident light primarily impacts the adaxial surface of the rosette leaves and is exposed

236 to adverse conditions more than the abaxial surface.

237 In our study, wild type individuals compared to Spe exhibited a higher maximal

238 photosynthetic capacity both when grown under low light as well as high light. At

239 saturating $\mathrm{CO}_{2}$ and light, the rates of $\mathrm{CO}_{2}$ assimilation were always higher for the wild

240 type compared to C. apetala (Fig. 5, A and B). This points to a limitation at the level of

241 electron transport and would cause a disadvantage for Spe. However, as can be taken

242 from the initial slopes of the $A / C_{i}$ curves, under ambient conditions with limiting $\mathrm{CO}_{2}$

243 concentrations up to $400 \mathrm{ppm}$, only slight differences were apparent when both types

244 were compared (Fig. 5, C and D).

245 One way to explain the coexistence of wild type and Spe in the same habitat is

246 based on the fact that the flowering phenology of both types differs. Wild-type plants

247 flower earlier by several days after sowing under greenhouse conditions (Hameister et

248 al. 2009, 2013) as well as under field conditions at the Botanical Garden of Osnabrueck

249 (Hameister and Neuffer 2017). The appearance of the inflorescences was monitored

250 also for sister plants after transfer to field conditions in the Botanical Garden in

251 Osnabrück (Fig. 6). On average flowering started two weeks later in Spe individuals as

252 compared to wild type. This might be explained by the disadvantage of Spe over the

253 total growth period due to somewhat lower photosynthetic capacity and consequently a 
254 lower growth rate resulting in a delay of biomass production in the vegetative stage.

255 Either due to the difference in the nutritional status or due to environmental signals,

256 flowering induction occurs significantly later in Spe thus leading to a temporal niche for

257 successful pollination and seed set. A small but stable population of $C$. apetala can

258 apparently coexist in the presence of the large wild-type population. Both types might be

259 adapted to slight differences in their growth properties and the environment by growing

260 in the rosette stage for a longer or shorter time resulting in a difference in flowering time

261 of about two weeks. Taken together, the selection pressure for both types is apparently

262 similar leading to stable populations growing side by side.

\section{Conclusions}

In this study, we were able to analyse two independent sympatrically occurring populations of Shepherd's Purse. These two populations (wild type and Spe) occur intermingled with each other in stable frequencies of 9:1 over the years. This situation is rather specific and the question arose: What are the characters enabling these populations to coexist as they actually do? Both populations are isolated by strong (selfing) and smooth (flowering, reduced pollen growth activity between taxa) barriers. We have been able here to quantify anatomical and physiological traits which, with all 272 probability, stay under selection pressure. Of course, many more characters are

273 included in the ecotypic differentiation and already have been studied elsewhere (e.g.

274 seed production). Here, in Spe, photosynthetic capacity appears to be lower, while 275 growing for a longer time in the vegetative stage and later flowering induction. As both 276 populations occur in stable frequencies, the selection pressure on single traits might be 
277 different, however, when combined, they seem to be neutralized. The specific

278 combination of characters in each taxon is linked due to predominantly selfing.

279

$280 \quad$ Acknowledgements

281 We would like to thank Jana Brunkhorst for performing the analyses and Rudi

282 Grupe for technical assistance.

283

284

285

286

287

\section{References}

Aksoy A, Hale WHG, Dixon JM. 1999. Towards a simplified taxonomy of Capsella bursa-pastoris (L.) Medik. (Brassicaceae). Watsonia 22: 243-250.

Almquist E. 1907. Studien über die Capsella bursa pastoris (L.). Acta Horti 288 Bergiani 4 No. 6: 1-92.

Hameister S, Neuffer B, Bleeker W. 2009. Genetic differentiation and 290 reproductive isolation of a naturally occurring floral homeotic mutant within a wild-type population of Capsella bursa-pastoris (Brassicaceae). Molecular Ecology 18: 2659292 2667.

B. 2017. Establishment of a natural floral variant of 294 Shepherd's Purse in the wild: analysis of life-history traits in 'Capsella apetala' 295 (Brassicaceae). Plant Ecology and Evolution 150: 67-75.

Hameister S, Nutt P, Theißen G, Neuffer B. 2013. Mapping a floral trait in (L.) Medik. FLORA 208: 641-647. 
300 Theissen G. 2006. Catching a 'hopeful monster': Sheperd's Purse (Capsella bursa-

301 pastoris) as a model system to study the evolution of flower development. Journal of

302 Experimental Botany 57: 3531-3542.

lanetta PPM, Begg G, Hawes C, Young M, Russell J, Squire GR. 2007.

304 Variation in Capsella (shepherd's purse): an example of intraspecific functional diversity.

305 Physiologia Plantarum 129: 542-554.

Linde M, Diel S, Neuffer B. 2001. Flowering ecotypes of Capsella bursa-pastoris

(L.) Medik. (Brassicaceae) analysed by a cosegregation of phenotypic characters (QTL) and molecular markers. Annals of Botany 87: 91-99.

Neuffer B, Bernhardt KG, Hurka H, Kropf M. 2011. Monitoring population and gene pool dynamics of the annual species Capsella bursa-pastoris (Brassicaceae) -

311 initiation of a long-term genetic monitoring and a review of relevant species traits.

312 Biodiversity and Conservation 20: 309-323.

Neuffer B, Linde M. 1999. Capsella bursa-pastoris - Colonization and

314 adaptation; a globe-trotter conquers the world. In: van Raamsdonk LWD, den Nijs JCM,

315 eds. Plant Evolution in Man-Made Habitats. Proceedings of the VIIth International IOPB

316 Symposium 1998, pp. 49-72.

317 Neuffer B, Paetsch M. 2013. Flower morphology and pollen germination in the 318 genus Capsella (Brassicaceae). FLORA 208: 626-640.

319 Neuffer B, Wesse C, Voss I, Scheibe R. 2018. The role of ecotypic variation in

320 driving worldwide colonization by a cosmopolitan plant. AoB Plants 10: 1-20. 
322 system to study the evolutionary relevance of floral homeotic mutants. Plant

323 Systematics and Evolution 259: 217-235.

324 Opiz PM. 1821. 2. Capsella apetala Opiz. Eine neue merkwürdige Pflanze. 325 FLORA 4 (II): 436-443.

326 Reichert H. 1998. Eine kronblattlose Sippe des Hirtentäschels (Capsella bursa327 pastoris) seit Jahren bestandsbildend bei Gau-Odernheim/Rheinhessen. Hessische 328 Floristische Rundbriefe 47: 53-55.

329 Shull H. 1909. Bursa bursa-pastoris and Bursa heegeri: biotypes and hybrids. 330 Carnegy Institution of Washington Publication 112: 3-56.

331 Shull H. 1911. Defective inheritance-ratios in Bursa hybrids. Verhandlungen des 332 Naturhistorischen Vereins in Brünn 49: 156-168. 


\section{Figure 1}

\section{Flower morphology}

Figure 1 Typical wild-type flower (A arrow points to the petal) and its typical pollinator, a wild bee (D). Typical decandric flower (C) and its typical pollinator, a hoverfly (E). Proof for a rare hybrid between both flower types with a developing petal and pollen sacs below (B). In the field, both types are growing in mixed populations (F). Fotos: Gitta Schüttler, Birgit von Höveling.

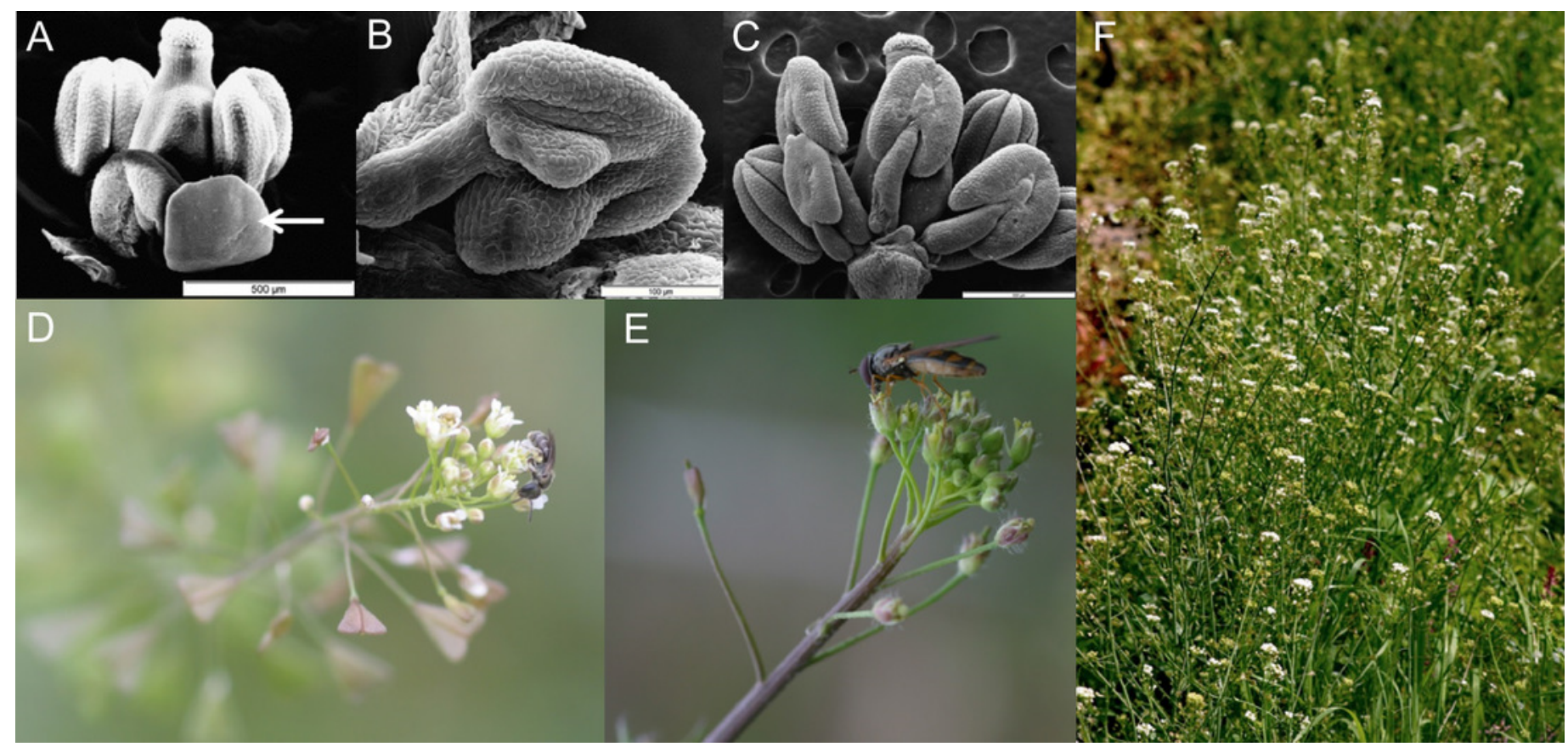




\section{Figure 2}

Habitus of individual plants cultivated under different light conditions

Habitus of individual plants of the same age ( $8^{\text {th }}$ to $9^{\text {th }}$ week after sowing) that had been cultivated under different light conditions. The inflorescence shoot was distorted since the light source was mounted $20 \mathrm{~cm}$ above the rosettes.

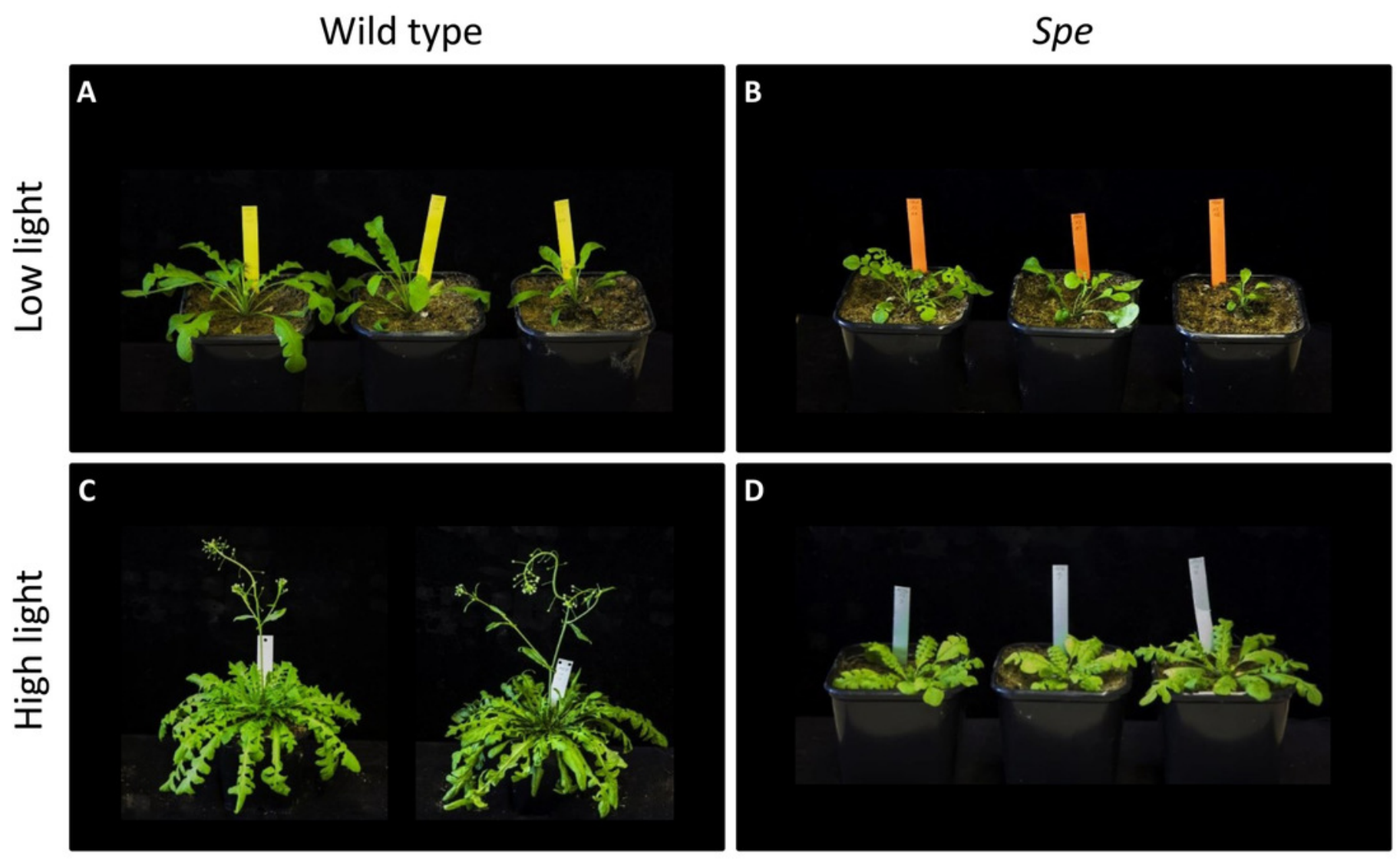


Figure 3

Stomata density of plants grown under high-light conditions.

Microscopical views of stomata distribution of plants grown under high-light conditions. Nail polish tracks of upper and lower leaf surfaces were taken. Black scale bar to avoid different font sizes.
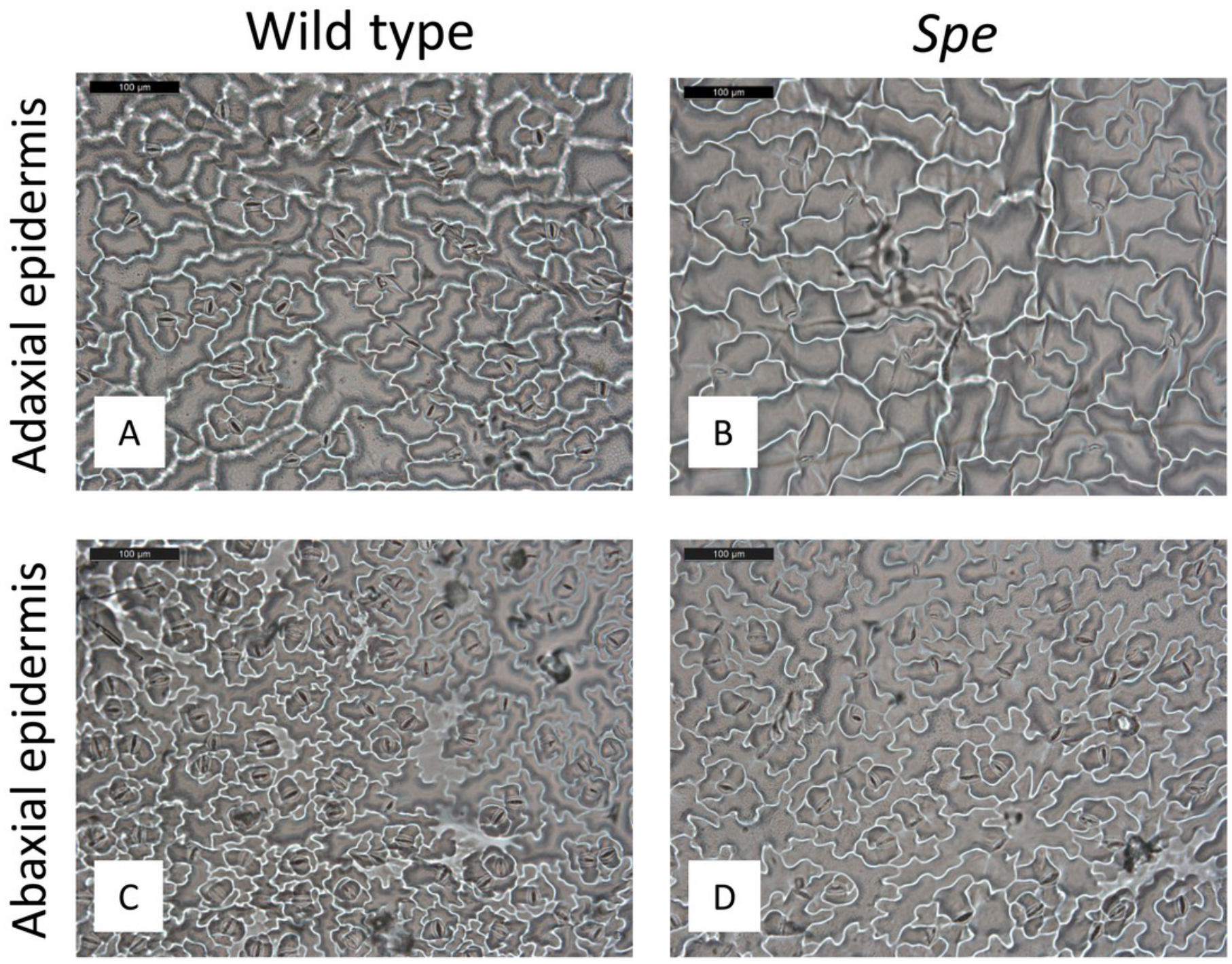
Figure 4

Stomata density

Stomata density of wild-type $C$. bursa-pastoris versus $C$. apetala (= Spe) grown under different light conditions. For significant differences between experimental groups see Suppl. Table 1.
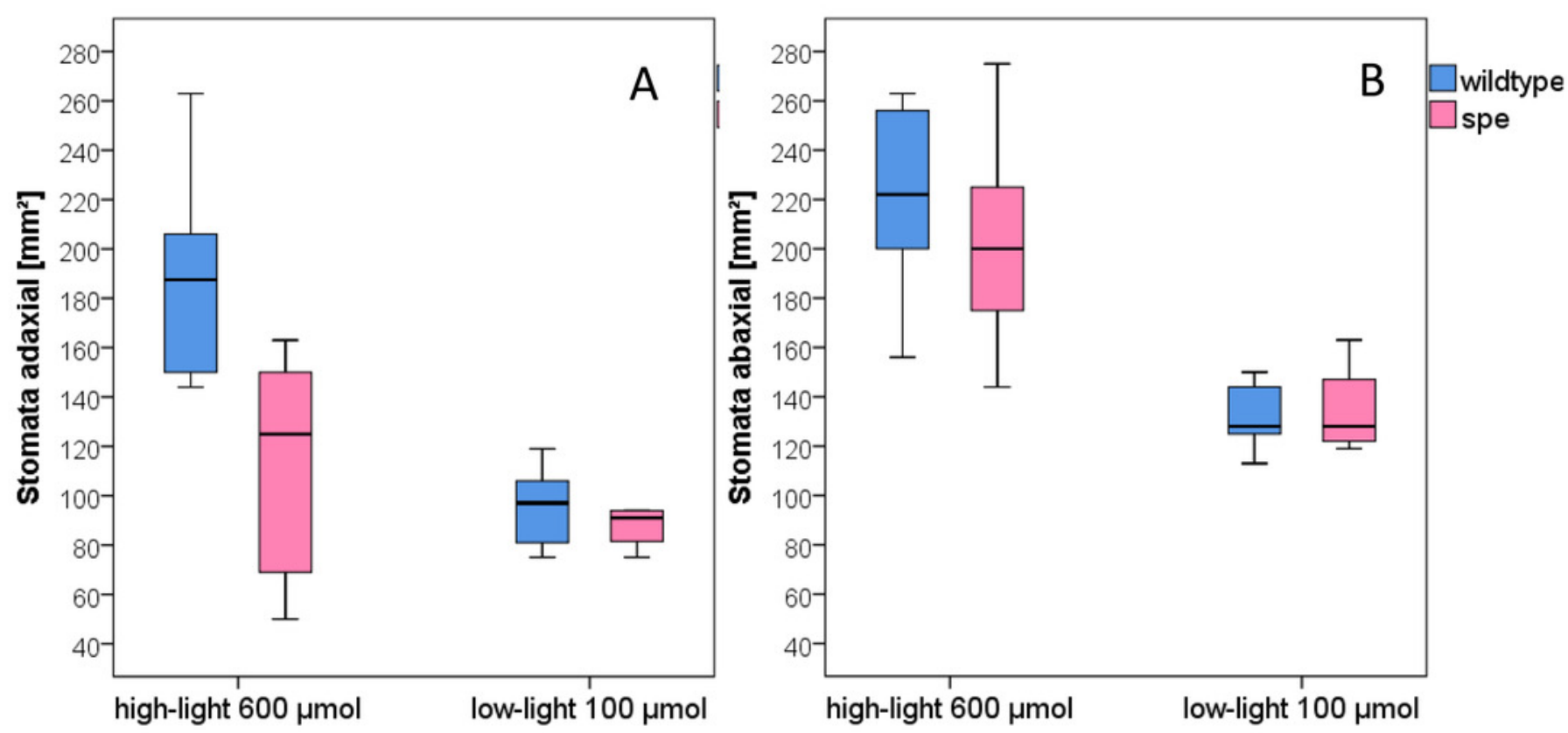


\section{Figure 5}

$\mathrm{CO}_{2}$-concentration dependence of the rate of $\mathrm{CO}_{2}$ assimilation

Figure $5 \mathrm{CO}_{2}$-concentration dependence of the rate of $\mathrm{CO}_{2}$ assimilation of wild type (WT, five individuals low light, seven individuals high light) and C. apetala (Spe, three individuals lowlight, seven individuals high light) grown under different light conditions. The plants had been

grown either under low-light ( $\mathbf{A}$ and $\mathbf{C}$ ) or under high-light conditions (B and $\mathbf{D}$ ), respectively. Determination of the rates of $\mathrm{CO}_{2}$ assimilation was performed under saturating light using one leaf for each individual as described in Material and Methods. A and B: After application of descending $\mathrm{CO}_{2}$ concentrations, the internal $\mathrm{CO}_{2}$ concentration $\left(\mathrm{C}_{\mathrm{i}}\right)$ was calculated in each case, and similar $\mathrm{C}_{\mathrm{i}}$ values were clustered (horizontal error bars). Stomata aperture was recorded for each measurement and is shown in Suppl. Fig. 1. B and D: Single measurements in the linear range up to $350 \mathrm{ppm}$ were plotted against $\mathrm{C}_{\mathrm{i}}$. 

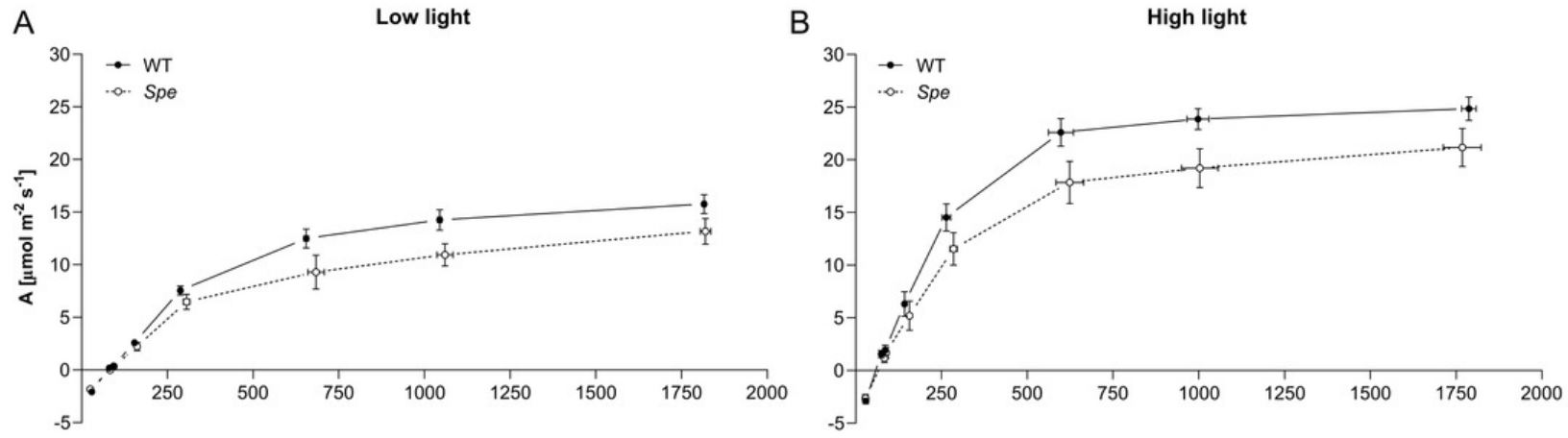

C

D
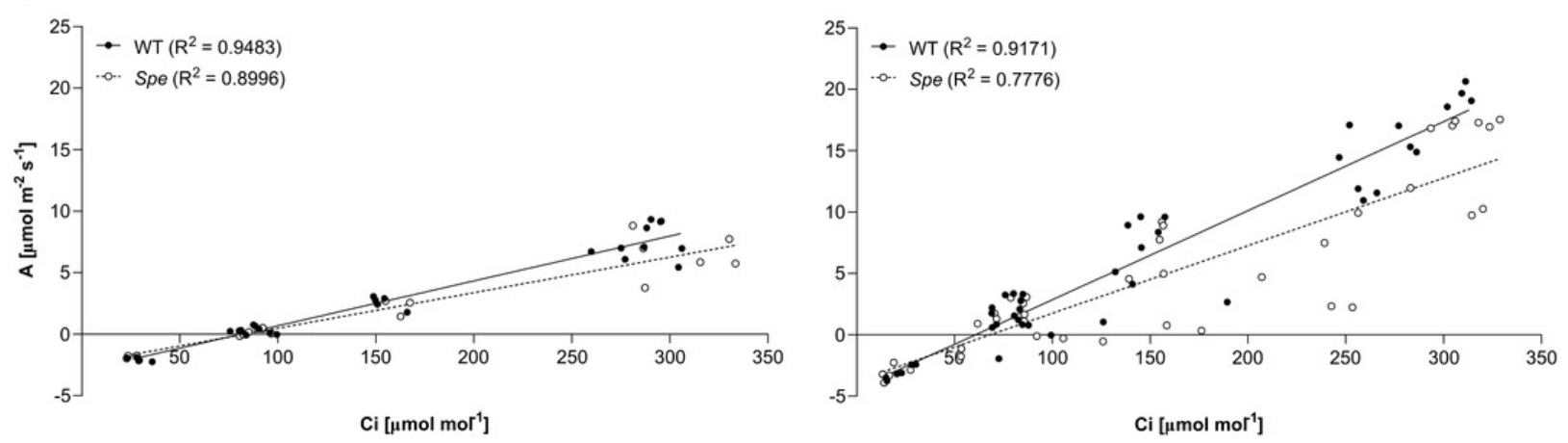
Figure 6

Onset of flowering in days after sowing.

Sister individuals of the plants that had been used for the physiological and anatomical analyses have been planted into the experimental field of the Botanical Garden Osnabrück on day 70 after sowing.

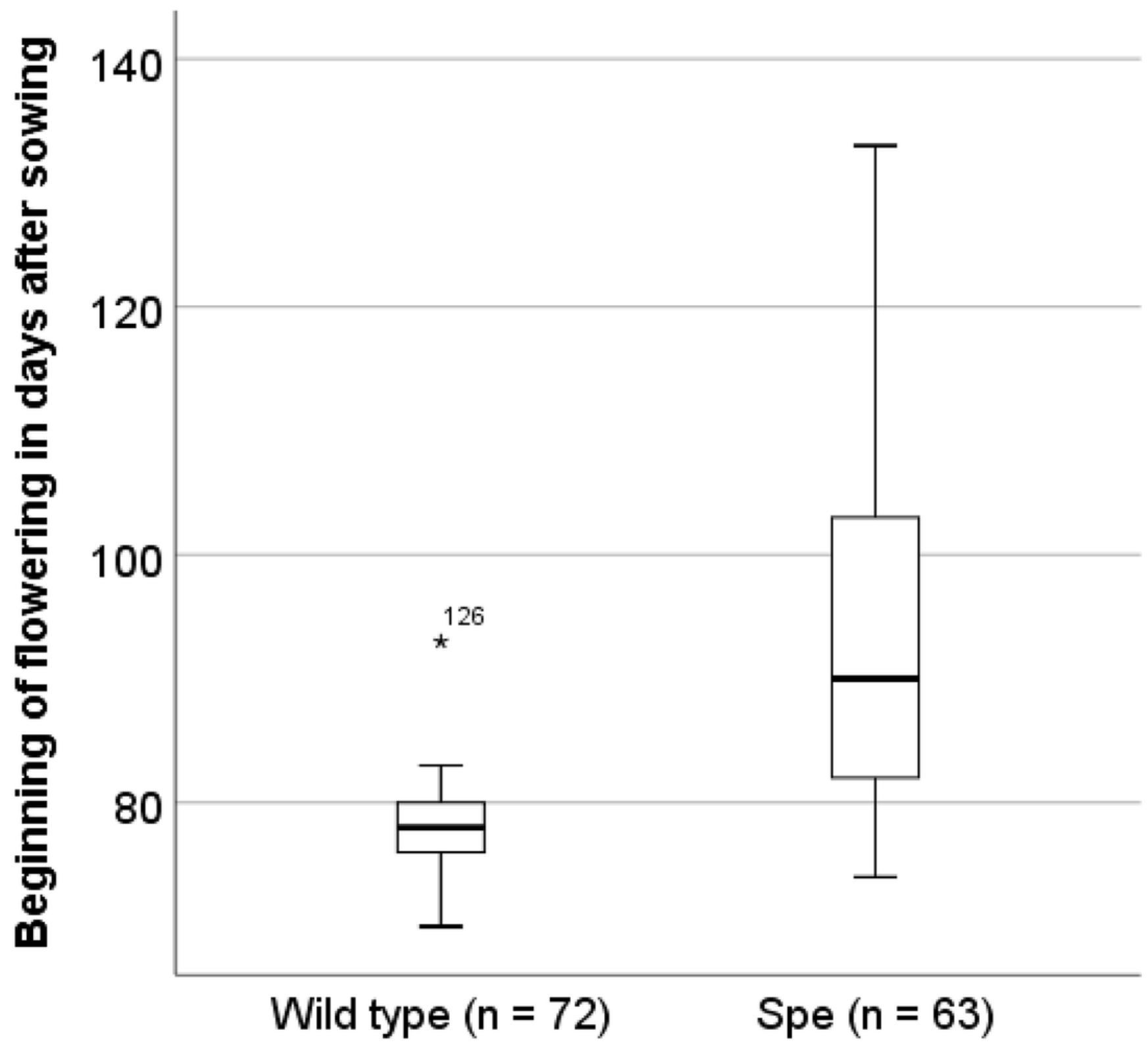

